\title{
Evaluation of Impact of Happiness on Academic Performance among Medical Students of Rawalpindi Medical University, Pakistan
}

\author{
Tayyab Mumtaz Khan, Sana Mansoor, Munazzah Kaleem, Muhammad Shahid Zafar, Anisa Sohail, \\ Sheema Nauman, Shahrukh Khan, Muhammad Hamad Qadeer, Muhammad Hashaam Yasir, \\ Manahil Jamil, Madeeha Mumtaz, and Hina Mansoor
}

\section{ABSTRACT}

Happiness is a collection of various kinds of emotions including positive and negative because of satisfaction in life. Happiness affects almost every aspect of life, however, among students, its most important impact is on their academic performance. Academic performance is positively affected by happiness and subsequently their performance as a physician. Therefore, our current study is set to assess the impact of happiness on academic performance among final-year medical students of Rawalpindi Medical University Pakistan. This may provide us a new way to bring improvement in academic performance of medical students. This descriptive crosssectional study was carried out among final-year medical students of Rawalpindi Medical University in January 2020. Collection of data was accomplished with the help of two questionnaires including Oxford Happiness Questionnaire for happiness assessment and self-structured questionnaire which was developed to obtain required data about demographic details and marks in last professional examination. Students who had diagnosed any physical and mental illness were excluded. From total of 223 students who were enrolled at the beginning of study, only 186 returned correctly filled questionnaires so final sample size became 186 . Data analysis was completed through SPSS v.25.0. Different statistical tests including Independent sample t-test, Chi-square test, Pearson's correlation, and linear regression were used to assess the study variables. Statistically significant and strong positive association was noted between happiness and academic performance of students $(p=0.000)$. To evaluate the direction and strength of association between happiness and academic performance, Pearson's correlation coefficient was calculated, and it was 0.809 with pvalue 0.000). Difference in happiness score between male students and female students $(p=0.015)$ and between boarder students and non-boarder students $(p=0.000)$ was statistically significant. Likewise, the difference in academic performance that was assessed through marks in last professional examination was also statistically significant between male student and female students $(p=0.001)$ and between boarder students and non-boarder students $(p=0.000)$ was also statistically significant. With $p$-value of 0.000 for $F$ test, simple linear regression model was valid. Value of unstandardized regression Coefficient (B) was 61.40 . $R^{2}$ was $0.655(65.5 \%)$. Our study overall shows higher happiness score and better academic performance among female and non-boarder students relative to male and boarder students. This current study also indicates statistically significant and strong positive association between happiness and academic performance, which means that increase in happiness increases the academic performance of students and vice versa. So, with the implementation of appropriate measures for the increase in happiness we can bring enhancement in academic performance of medical students.

Keywords: Evaluation, Impact, Happiness, Academic Performance, Medical Students, Rawalpindi Medical University.
Published Online: December 15, 2020

ISSN: $2593-8339$

DOI: 10.24018 / ejmed.2020.2.6.603

\section{Tayyab Mumtaz Khan*}

Rawalpindi Medical University, Pakistan.

(e-mail: tayyab.mkhan98@gmail.com)

Sana Mansoor

Rawalpindi Medical University, Pakistan. Munazzah Kaleem

Rawalpindi Medical University, Pakistan. Muhammad Shahid Zafar

The University of Agriculture, Pakistan. Anisa Sohail

Pir Mehr Ali Shah-Arid Agriculture University, Pakistan.

Sheema Nauman

The University of Agriculture, Pakistan.

Shahrukh Khan

University of Veterinary and Animal

Sciences, Pakistan.

Muhammad Hamad Qadeer

University of Veterinary and Animal

Sciences, Pakistan.

Muhammad Hashaam Yasir

The University of Agriculture, Pakistan.

Manahil Jamil

Rawalpindi Medical University, Pakistan.

Madeeha Mumtaz

Lahore College for Women University, Pakistan.

Hina Mansoor

National University of Modern Languages, Pakistan.

*Corresponding Author

\section{INTRODUCTION}

Happiness is an intricate term, assessed by subjective wellbeing which encompasses 3 components: positive effects, negative effects, and life satisfaction [1]. Positive effects constitute happiness, elation, excitedness, alertness which brings about serenity, contentment, gratification and calmness [2]. Whilst negative effects involve stress, nervousness etc. generating sadness, boredom, and depression [3]. These effects are the part and parcel of our lives and influence our thinking perspective and subsequently our actions and performance in various aspects 
of life. Psychologically, happiness is the perspective everyone has about their life [4], [5]. Moreover, in literature, various studies have different ideas about happiness. Some suppose it to be a state of positive emotions while some consider it as a sense of contentment in general [6]. In either way, it has direct influential effects on everyday life situations [7]. As mentioned above that happiness is considered as either a state of positive emotions or state of satisfaction, this may be the reason that happier people are better able to confront various life situations as compared to unhappy ones and subsequently give better performance in daily life activities [3], [4]. Academic performance depicts intellectual growth and development of a student, bringing to light the ambition of entire educational structure [8]. Academic accomplishment is the best marker of judgement of educational system [9]. Retrospectively, academic performance rests on the pillars of numerous factors such as life satisfaction, emotional expressivity, emotional regulation, academic motivation and a lot more [10], [11]. Unfortunately, our society has always emphasized on the academic performance of the student without knowing about the foundation on which it rests [12]. Analysis have shown that the educational institutions that highlights the role of these factors that affect academic performance and provides favorable atmosphere to the students, deliver more promising results [10], [13]. Relationship between happiness and goal achievements have been assessed in a lot of studies [7], [14],[15]. As for the students, happiness can be considered as a substantial factor in their lives, because happiness itself not only affects academic achievements, but it is also get affected by academic achievements and success along with a lot of other factors [2], [10], [16]. It may be more affected in culture where educational achievement is a priority above all [7]. Studies across the border shows that happier the students the more academically sound and prosperous they are [4], [17]. A general trend was also observed in different countries showing that those having high academic achievements also had the highest average happiness score [1]. Along with international researches in which relationship between happiness and academic performance have been evaluated, in literature, a study that was conducted at national level, has also noted similar relationship between happiness and academic performance [18]. Moreover, it has been discovered that happiness and gratification in the students bring optimism in student which open new success pathways helps them to reach the zenith of their career [19]. Although, at international level and national level many studies have been conducted in which impact of happiness on academic performance among students has been evaluated [9], [13], [18]. However, at local level, no study has been conducted for the assessment of relationship between happiness and academic performance. So, in absence of a study for the evaluation of impact of happiness on academic performance, our current study aims to assess the impact of happiness on academic performance, and if the results of our study show that happiness affects academic performance and affects positively then by applying interventions that increase happiness level, we would be able to bring improvement in academic performance, subsequently, we could provide better physicians to the world.

\section{MATERIAL AND METHODS}

\section{A. Study Design and Study Population}

This descriptive cross-sectional study was conducted at Rawalpindi Medical University among final year medical students during January 2020. Out of 375 students of final year, 223 students were recruited in the study based on inclusion and exclusion criteria. Only those final year students were enrolled in study, who were physically and mentally healthy and were willing to participate with the exclusion of those, who had any mental and physical illness because any kind of illness could affect the happiness levels and subsequently study results. Two questionnaires were used for data collection. After complete explanation of purpose of study and informed consent was taken from all participant students and then two questionnaires were given to all students. Out of 223participants, only186 students returned properly filled questionnaires. So, the response rate was $83.408 \%$ (students returned properly filled questionnaires). Hence, final sample size for this study was 186.

\section{B. Assessment of Characteristics of Study Population and Academic Performance}

A Self-structured questionnaire was used to get information about demographic details and academic performance. There were two portions of self-structured questionnaire. First portion was about demographics details that included age, gender, and boarding status. Second part was about academic performance in which marks in last professional examination was asked. On the basis of marks in last professional exam, participants were categorized into two categories which included high achievers and low achievers. Students with 700 marks or above, out of 1000 marks were considered high achievers ( $70 \%$ or above) while students with less than 700 marks (less than 70\%) were considered as low achievers.

\section{Assessment of Happiness}

Happiness was assessed through internationally used questionnaire for happiness known as Oxford Happiness Questionnaire (OHQ). Its reliability has been established in different studies internationally [25]-[27]. It has 29 items and scores ranges from 1-6. Interpretation of score was done through Interpreting method of Stephen Wright [25]. Seven levels of Happiness were obtained after interpretation. These seven levels of happiness included not happy:1-2, somewhat unhappy: 2-3, not particularly happy or unhappy:3-4, somewhat happy or moderately happy:4, rather happy; pretty happy.4-5, very happy:5-6, and too happy: 6 . Higher score indicating higher level of happiness.

\section{Data Analysis}

A descriptive data analysis of study variables was carried out through SPSS 25version. To check the reliability of OHQ a pilot study was conducted on 35 participants through which Cronbach alpha value was calculated and it was 0.816 indicating high reliability of OHQ. Independent sample t-test was applied for the assessment of differences in happiness and academic performance across the gender and boarding status. Direction and strength of the correlation between Happiness and academic performance was checked by using 
chi-squared test and Pearson's correlation. Finally, simple linear regression was used for the assessment of predictive ability of happiness for professional exam marks. The value of $\mathrm{p}$ of less than 0.05 was considered significant statistically.

\section{RESULTS}

The study population comprised 186students, with mean age of 23.16 years with standard deviation (SD) of \pm 1.025 . The mean score of happiness for study population was 4.03 with SD of \pm 0.893 and the mean of marks was 709.90 with $\mathrm{SD}$ of \pm 67.79 in last professional examination.

Table 1 indicates the parameters of study population together with their cross-tabulation with study variables and chi-square analysis for assessment of relationship between happiness and academic performance.

Table 2 summarizes the difference in mean score of happiness based on gender and boarding status on happiness scale (Oxford Happiness Scale) and the difference in marks of professional examination along with results of independent sample t-test.

Table 3 shows difference in mean score of happiness on happiness scale between high achievers and low achievers together with independent sample t-test and its p-value. Happiness mean score was higher among high achievers as compared to low achievers and this difference was significant statistically. In table, the Pearson correlation analysis elaborates statistically significant association between happiness and academic performance, and it was strong and positive. It indicates that higher happiness score was linked with higher marks in professional examination.

Table 4 elaborates the results of simple linear regression model along with its validity. F test was highly significant with $p$ value of 0.000 , which means that regression model was valid, and happiness was a significant predictor of marks in professional examination. $\mathrm{R}^{2}$ value was 0.655 (65.5\%) which means that $65.5 \%$ variation in student's academic performance was due to happiness while remaining $34.5 \%$ variance could be because covert variables that were not included in regression model. The beta coefficient was positive for happiness scale with statistically significant $\mathrm{p}$ value (0.000). The value of regression coefficient, $b$ was 61.40 which means that one unit increase in happiness score would lead to increase of 61.40 marks in professional examination of participants as the value of $b$ was positive.

Results of our study indicates that happiness is significantly and positively associated with academic performance of Final year MBBS medical students of Rawalpindi Medical University and higher happiness increases the academic performance of students.

TABLE 1: StUdy POPULATION PARAMETERS ALONG WITH THEIR CROSS-TABULATION WITH STUDY VARIABLES AND CHI-SQUARE ANALYSIS.

\begin{tabular}{|c|c|c|c|c|c|c|c|c|c|c|}
\hline \multicolumn{11}{|c|}{ Cross-Tabulation and chi-square analysis } \\
\hline \multicolumn{2}{|c|}{ Parameter } & \multicolumn{2}{|c|}{ Academic Performance } & \multicolumn{7}{|c|}{ Happiness Levels } \\
\hline \multicolumn{2}{|c|}{ Total $=186$} & $\begin{array}{c}\text { High } \\
\text { Achiever }\end{array}$ & $\begin{array}{c}\text { Low } \\
\text { Achiever }\end{array}$ & $\begin{array}{l}\text { Not } \\
\text { Happy }\end{array}$ & $\begin{array}{l}\text { Somewhat } \\
\text { Unhappy }\end{array}$ & $\begin{array}{c}\text { Not } \\
\text { Particularly } \\
\text { Happy }\end{array}$ & $\begin{array}{c}\text { Moderately } \\
\text { Happy }\end{array}$ & $\begin{array}{l}\text { Pretty } \\
\text { Happy }\end{array}$ & $\begin{array}{l}\text { Very } \\
\text { Happy }\end{array}$ & $\begin{array}{l}\text { Too } \\
\text { Happy }\end{array}$ \\
\hline \multirow{2}{*}{ Gender } & $\begin{array}{l}\text { Female } \\
(\mathrm{n}=109)\end{array}$ & $68(62.3 \%)$ & $41(37.6 \%)$ & $00(0.0 \%)$ & $20(18.4 \%)$ & $14(12.8 \%)$ & $34(31.2 \%)$ & $33(30.3 \%)$ & $00(0.0 \%)$ & $8(7.4 \%)$ \\
\hline & $\begin{array}{l}\text { Male } \\
(\mathrm{n}=77)\end{array}$ & $34(44.2 \%)$ & $43(55.8 \%)$ & $00(0.0 \%)$ & $33(42.9 \%)$ & $4(5.2 \%)$ & $16(20.8 \%)$ & $20(25.9 \%)$ & $00(0.0 \%)$ & $4(5.2 \%)$ \\
\hline \multirow{2}{*}{$\begin{array}{l}\text { Boarding- } \\
\text { Status }\end{array}$} & $\begin{array}{c}\text { Boarder } \\
(\mathrm{n}=98)\end{array}$ & $41(41.8 \%)$ & $57(58.2 \%)$ & $00(0.0 \%)$ & $43(43.8 \%)$ & $6(6.2 \%)$ & $28(28.6 \%)$ & $19(19.4 \%)$ & $00(0.0 \%)$ & $2(2.1 \%)$ \\
\hline & $\begin{array}{c}\text { Non-Boarder } \\
(\mathrm{n}=88)\end{array}$ & $61(69.3 \%)$ & $27(30.7 \%)$ & $00(0.0 \%)$ & $10(11.4 \%)$ & $12(13.6 \%)$ & $22(25.0 \%)$ & $34(38.63 \%)$ & $00(0.0 \%)$ & $10(11.4 \%)$ \\
\hline
\end{tabular}

Happiness and Academic Performance had Significant association $(\mathrm{p}=0.000)$.

TABLE 2: DIFFERENCE IN OHQ SCORE AND MARKS IN PROFESSIONAL EXAMINATION BASED ON GENDER AND BOARDING STATUS.

\begin{tabular}{|c|c|c|c|c|c|c|}
\hline \multirow[b]{2}{*}{ Parameter } & \multicolumn{3}{|c|}{ Gender } & \multicolumn{3}{|c|}{ Boarding Status } \\
\hline & Female & Male & $\begin{array}{l}\text { Independent } \\
\text { Sample t-test }\end{array}$ & Non-Boarder & Boarder & $\begin{array}{l}\text { Independent } \\
\text { Sample t-test }\end{array}$ \\
\hline $\begin{array}{c}\text { OHQ } \\
(\mathrm{Mean} \pm \mathrm{SD})\end{array}$ & $4.17 \pm 0.86$ & $3.84 \pm 0.91$ & 0.015 & $4.37 \pm 0.89$ & $3.73 \pm 0.79$ & 0.000 \\
\hline $\begin{array}{l}\text { Marks in last professional } \\
\text { Examination (Mean } \pm \text { SD) }\end{array}$ & $723.81 \pm 63.50$ & $690.22 \pm 69.18$ & 0.001 & $735.23 \pm 67.47$ & $687.16 \pm 59.81$ & 0.000 \\
\hline
\end{tabular}

TABLE3: PEARSON'S CORRELATION OF HAPPINESS SCORE WITH ACADEMIC PERFORMANCE AND MARKS IN LAST PROFESSIONAL EXAMINATION (HAPPINESS SCALE = OXFORD HAPPINESS QUESTIONNAIRE)

\begin{tabular}{cccccc} 
& \multicolumn{4}{c}{ SCALE = OXFORD HAPPINESS QUESTIONNAIRE) } \\
\cline { 2 - 5 } Parameters & $\begin{array}{c}\text { High } \\
\text { Achievers }\end{array}$ & $\begin{array}{c}\text { Low } \\
\text { Achievers }\end{array}$ & $\begin{array}{c}\text { Independent } \\
\text { Sample t-test }\end{array}$ & $\begin{array}{c}\text { Correlation } \\
\text { coefficient } \\
(\mathrm{r})\end{array}$ & p-value \\
\hline $\begin{array}{c}\text { OHQ } \\
\text { Score }\end{array}$ & $4.54 \pm 0.79$ & $3.42 \pm 0.57$ & 0.000 & 0.809 & 0.000 \\
\hline
\end{tabular}

TABLE4: SIMPLE LINEAR REGRESSION MODEL FOR MARKS IN LAST PROFESSIONAL EXAMINATION (HAPPINESS SCALE= OXFORD HAPPINESS QUESTIONNAIRE)

\begin{tabular}{ccccccc}
\hline Variable & $\mathrm{R}$ & $\mathrm{R}^{2}$ & $\begin{array}{c}\text { Unstandardized } \\
\text { Regression Coefficient } \\
(\mathrm{B})\end{array}$ & $\begin{array}{c}95 \% \\
\text { CI }\end{array}$ & $\begin{array}{c}\text { Standardized } \\
\text { Regression } \\
\text { Coefficient (Beta) }\end{array}$ \\
\hline Happiness Score & 0.809 & 0.655 & 61.40 & 54.92 to 67.88 & 0.809 & 18.68 \\
\hline
\end{tabular}

The Regression Model was significant because $F$ test was significant with p value of 0.000 . $(\mathrm{F}=349.02)$. 


\section{DISCUSSION}

Happiness is one of the important psychological factors of our lives that affects almost every aspect of our lives. In Our study we have assessed the impact of happiness on academic performance among final year medical students of Rawalpindi Medical University Pakistan. Our study provides valuable information about the impact of happiness on academic performance among final year MBBS students of Rawalpindi Medical University. Moreover, our current study also shows difference in happiness and academic performance among students based on their gender and boarding status.

In the beginning of data analysis of our study, we noticed the difference in happiness score among students on the basis their gender and boarding status. We noted that female students had higher mean score on Oxford Happiness Questionnaire which means that female students were happier in comparison with male students and we also found that this difference was statistically significant $(\mathrm{p}=0.015)$ through independent sample t-test. In literature, we found a study that was conducted at Iran, with similar finding in which females were happier and had higher score on happiness scale as compare to males [9]. However, a study also reported no significant association between gender and happiness [20]. To support our study finding we can say that the higher happiness level among female students could be because of more expressive nature of females and release of emotions through catharsis and better academic achievements in student life. Then, in next step, statistically significant difference in happiness between boarders and non-boarders was also noted by using independent sample ttest with p-value 0.000. Boarder students had lower happiness level relative to non-boarder students which means boarder students had lower score on happiness scale. Lower level of happiness means that they had poor mental health and less satisfaction in their lives, and poor mental health and less satisfaction among boarders haven been noted among boarders by two studies that were conducted at Thailand and Germany respectively [21], [22]. There are many reasons that could be the cause of lower level of happiness among students live in hostels, including bullying, unfamiliar environment, no emotional support, that they normally get from their family and close friends and more tasks to deal with and strict routine at hostel.

On further data analysis, we observed the difference in academic performance among enrolled students similarly based on their gender and boarding status. Academic performance was higher among female students in comparison with male students, and this difference was statistically significant $(\mathrm{p}=0.000)$. Better Academic performance among female students as compare to male students was also noticed in a study that was conducted at Iran [9]. After observing difference in academic performance between female students and male students, the difference in academic performance between boarder students and nonboarder was noticed and it also was statistically significant (0.000) with higher academic performance among nonboarder students relative to boarder students. Regarding difference in academic performance among boarder and nonboarder a study that was also conducted among Pakistani medical students also had similar finding that non-boarders had better academic performance than boarders, however, an Indian study reported conflicting finding and according to results of this study, boarder students have higher academic performance relative to non-boarders students [23], [24].

At the end of data analysis, after highlighting the difference in happiness and academic performance among students based on their gender and boarding status. we assessed the association between happiness and academic performance among final year medical students of Rawalpindi Medical University. Statistically significant association was noted between happiness and academic performance with $\mathrm{p}$ value of 0.000 . and it was assessed by using chi-square test. Furthermore, to evaluate the direction and strength of association between happiness and academic performance we applied Pearson's product moment correlation. We observed strong and positive association between happiness and academic performance with the correlation coefficient of 0.809 . Positive value of correlation coefficient indicates that increase in happiness leads to increase in academic performance. And then, for more elaboration of this association between happiness and academic performance and to support the results of chisquare and Pearson's product moment correlation. linear regression was applied. Overall regression model was valid because $\mathrm{F}$ test was statistically significant $(\mathrm{p}=0.000)$ and $\mathrm{R}^{2}$ was $0.655(65.5 \%)$ which means happiness can bring $65.5 \%$ variance in academic performance of students. During literature search, different studies with conflicting findings regarding the association of happiness and academic performance of students were found. Different studies that were conducted in various countries including Pakistan, Iran, support our study finding that happiness and academic performance have strong and positive association and agree with our study finding that increase in happiness leads to better academic performance among students [8], [9]. While a study that conducted in Philippines reported conflicting finding, that happiness has no impact on academic performance of students [3]. In the presence of findings in literature regarding the association of happiness and academic performance, that agrees with our study results, we support the idea that by increasing happiness we may be able to bring enhancement in the academic performance of students.

This study is first study in which we have assessed the relationship between happiness and academic performance among Pakistani medical students of Rawalpindi Medical University and this makes it unique in its approach. We have observed in our current study, that higher happiness levels among students leads to better academic performance. So, our study provides an idea that by implementation of different suitable measures that could increase happiness level among students, we may also be able to bring improvement in academic performance of students subsequently improvement self confidence level. Furthermore, increase in happiness would also lead to decrease in study related stress, anxiety, and depression. It should be compulsory for all educational institutions of every level including schools, colleges, and universities to organize workshops and session through which knowledge can be provided about psychological interventions and techniques 
for the increase in happiness levels after assessing level of awareness and attitudes of students towards their mental health. Students should be encouraged to participate in sports and extra-curricular and this would help them to cope with stress, anxiety and depression and increase in happiness level and subsequently improvement in academic performance. By increasing happiness and consequently academic performance among medical students, we would be able to provide better physicians to the world.

\section{CONCLUSION}

Results study shows that, happiness is significantly and positively associated with academic performance among MBBS medical students of Rawalpindi Medical University which means that increase in happiness will bring improvement in academic performance of students and vice versa. Happiness is higher among female, and non-boarder students as compare to male, and boarder students and this difference is statistically significant. Likewise, academic performance is higher among female and non- boarder students as compare to male and boarder students. This difference in academic performance is also statistically significant. So, our study encourages the idea that by increasing happiness via different suitable interventions we can upgrade the academic performance of students and consequently we can provide world with better physicians.

\section{REFERENCES}

[1] Suldo SM, Riley KN, Shaffer EJ. Academic correlates of children and adolescents' life satisfaction. School Psychology International. 2006 Dec;27(5):567-82.

[2] Amirzehni J, Abbasi S, Moharrami FA, Zareipour MA. Evaluation of Happiness and Its Relationship with Academic Achievement in Urmia Midwifery Students. Mintage Journal of Pharmaceutical \& Medical Sciences. 2018;7(sup4):18-21.

[3] Lumontod III RZ. Happiness and other factors behind examination performance of college students. International Journal of Research Studies in Psychology. 2018;7(2):85-99.

[4] Jun WH, Jo MJ. Factor affecting happiness among nursing students in South Korea. Journal of psychiatric and mental health nursing. 2016 Aug;23(6-7):419-26.

[5] Medvedev ON, Landhuis CE. Exploring constructs of well-being, happiness and quality of life. PeerJ. 2018 Jun 1;6:e4903.

[6] Xu W, Sun H, Zhu B, Bai W, Yu X, Duan R, Kou C, Li W. Analysis of factors affecting the high subjective well-being of Chinese residents based on the 2014 China family panel study. International journal of environmental research and public health. 2019 Jan;16(14):2566.

[7] Lyubomirsky S, King L, Diener E. The benefits of frequent positive affect: Does happiness lead to success?. Psychological bulletin. 2005 Nov;131(6):803.

[8] Bukhari SR, Khanam SJ. Relationship of academic performance and well-being in university students. Pakistan Journal of Medical Research. 2017 Oct 1;56(4):126-30.

[9] Tabbodi M, Rahgozar H, Makki Abadi MM. The relationship between happiness and academic achievements. European Online Journal of Natural and Social Sciences: Proceedings. 2015 Feb 19;4(1 (s)):pp-241.

[10] Kwon K, Hanrahan AR, Kupzyk KA. Emotional expressivity and emotion regulation: Relation to academic functioning among elementary school children. School Psychology Quarterly. 2017 Mar;32(1):75.

[11] Burr J, Beck Dallaghan GL. The relationship of emotions and burnout to medical students' academic performance. Teaching and learning in medicine. 2019 Oct 20;31(5):479-86

[12] Pekrun R, Lichtenfeld S, Marsh HW, Murayama K, Goetz T. Achievement emotions and academic performance: Longitudinal models of reciprocal effects. Child development. 2017 Sep;88(5):1653-70.

[13] Otaghi M, Sayehmiri K, Valizadeh R, Tavan H. Correlation Between Happiness and Academic Achievement in Iranian Students: A MetaAnalysis Letter. Shiraz E-Medical Journal. 2020 Mar 31;21(3).

[14] Lumontod III RZ. The role of goal concordance on happiness and college students' academic performance. International Journal of Research. 2019;8(1):63-78.

[15] Street H, Nathan P, Durkin K, Morling J, Dzahari MA, Carson J, Durkin E. Understanding the relationships between wellbeing, goalsetting and depression in children. Australian \& New Zealand Journal of Psychiatry. 2004 Mar;38(3):155-61.

[16] Mehrdadi A, Sadeghian S, Direkvand-Moghadam A, Hashemian A. Factors affecting happiness: a cross-sectional study in the Iranian youth. Journal of clinical and diagnostic research: JCDR. 2016 May;10(5):VC01.

[17] Shojaei F. The study of nursing student's gratification and hilarity as a mental health index. Iranian Journal of Nursing Research. $2012 \mathrm{Apr}$ 10;7(24):16-22.

[18] Manzoor A, Siddique A, Riaz F, Riaz A. Determining the impact of subjective well-being on academic achievement of children in district Faisalabad. Mediterranean Journal of Social Sciences. 2014 Nov 9;5(23):2673.

[19] Steptoe A. Happiness and health. Annual review of public health 2019 Apr 1;40:339-59.

[20] Mahon NE, Yarcheski A, Yarcheski TJ. Happiness as related to gender and health in early adolescents. Clinical nursing research. 2005 May;14(2):175-90.

[21] Akiyama T, Win T, Maung C, Ray P, Sakisaka K, Tanabe A, Kobayashi J, Jimba M. Mental health status among Burmese adolescent students living in boarding houses in Thailand: a crosssectional study. BMC Public Health. 2013 Dec 1;13(1):337.

[22] Pfeiffer JP, Pinquart M. Bullying in German boarding schools: A pilot study. School Psychology International. 2014 Dec;35(6):580-91.

[23] Altaf B, Rehman A, Ali FA. Comparison of Academic Performance among Boarders and Day-Scholars. Journal of Aziz Fatimah Medical \& Dental College. 2019 Nov 19;1(2):60-2.

[24] Jacob AM, Kaushik A. A Comparative Study to Assess the Health Status and Academic Progress among Day Scholars and Hostellers in a Selected College of Nursing in New Delhi. Int. J. Nurs. Midwif. Res. 2017;4(2)

[25] Hills P, Argyle M. The Oxford Happiness Questionnaire: a compact scale for the measurement of psychological well-being. Personality and individual differences. 2002 Nov 1;33(7):1073-82.

[26] Kashdan TB. The assessment of subjective well-being (issues raised by the Oxford Happiness Questionnaire). Personality and individual differences. 2004 Apr 1;36(5):1225-32.

[27] Abdel-Khalek AM. Measuring happiness with a single-item scale. Social Behavior and Personality: an international journal. 2006 Jan 1;34(2):139-50.

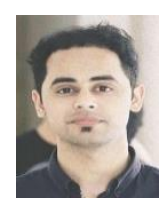

Tayyab Mumtaz Khan

Place and date of birth: Lahore, Pakistan 23-3-1996. Educational background: Final year MBBS, Rawalpindi Medical University Rawalpindi, Pakistan.

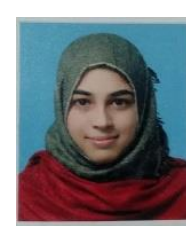

Sana Manoor

Place and date of birth: Sialkot, Pakistan. 14-91997.Educational background: Final year MBBS, Rawalpindi Medical University Rawalpindi, Pakistan.

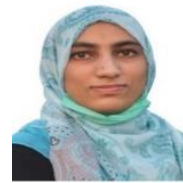

\section{Munazzah Kaleem}

Place and date of birth: Islamabad, Pakistan. 25-011996.

Educational Background : Final year MBBS, Rawalpindi MedicalUniversity Rawalpindi, Paksitan. 